medical colleague any difficulties they experience in adapting to work within a multidisciplinary team.

\section{Senior registrar training}

Senior registrars bring their own skills to the team. This should be acknowledged, and they need to be allowed to pursue existing interests within the new setting. The skills they need to be given the opportunity to acquire are subtly different from those appropriate to the junior trainee: SRs should be given an active role in management. They also need to be allowed experience of independent functioning in community settings. This could include, for example, the experience of setting up and maintaining liaison meetings with local services such as the Social Work Department. The supervision they require often relates to the chance to review progress in acquiring these skills, and in discussing wider aspects of liaison and community work, rather than the more specific case-oriented supervision appropriate to the junior trainee. We suggest that experience in community psychiatry is appropriate at both stages in training.

The hallmark of community psychiatry is its liability to change. Practice is constantly reviewed, reconsidered and adapted. This plasticity of function is important, and the ability to adapt should be encouraged in trainees. Hence it is appropriate to help trainees acquire an understanding of principles and methods of working which can be altered to suit any setting in which they later find themselves.

DENISE COIA

Florence Street Day Hospital

Cameron Stark

Gorbals, Glasgow

\section{References}

CONNOLly, J. \& MaRKs, I. (1989) Community oriented psychiatric care. Psychiatric Bulletin, 13, 26-27.

JONES, D. (1988) Registrar Training in a Psychiatric Service with a Community Emphasis. Unpublished Report.

SCOTT, J. \& WeBb, T. (1987) CTC Working Party Report: Training Implications of the Shift to Community-Orientated Psychiatric Practice. Unpublished Report.

\section{Community mental health teams}

\section{DeAR SIRS}

It seems to be assumed that community mental health teams are "a good thing" and that we should all be working in them. However, I have yet to see clear aims and goals set out for community health teams or a reasonable, controlled trial to indicate whether such methods of working are achieving goals better than conventional methods.
The way the teams seem to be working is that a member of the team, of whatever discipline, is allocated to the GP practice and the received wisdom is that this is of benefit to that practice and is a better way of delivering psychiatric care to people suffering from a psychiatric illness than other methods.

As there seems to be considerable pressure, particularly in the health district I work in, for the community health team method of working to be applied throughout the District in the manner described above, I think some objective assessment of this manner of working needs to be done. I have yet to see such a study carried out.

Maybe the DHSS should address itself to this question of objective assessment of new patterns of working. The alternative way of providing help for people with psychiatric problems at primary care level is for the practice itself to employ a practice counsellor. Maybe this is just as effective a way of providing the appropriate care with psychiatric backup for more serious problems.

I would be interested to see some discussion on this. There seems to be a major difficulty about leadership, and roles and responsibilities of team members.

\section{Milton Keynes General Hospital Milton Keynes}

N. H. WEIR

\section{Participating in primary care - a new model}

\section{DeAr Sirs}

We enjoyed Mitchell's excellent paper on psychiatric liaison attachment schemes (Psychiatric Bulletin, March 1989, 13, 135-137), but there are three points we should like to make. First, the percentage of consultant psychiatrists in Scotland who spend some time in primary care settings is even higher than he suggested - in fact $56 \%$ (Pullen \& Yellowlees, 1988). Second, it should be pointed out that the models described are not mutually exclusive. The Scottish survey showed that most psychiatrists use a mixture of models and, once in the primary care setting, become involved in a variety of activities with other members of the primary care team.

Finally, there are two major problems associated with trying to provide a liaison service to all general practitioners in a sector or district catchment area. Most models of liaison can only be offered economically to larger group practices or health centres (excluding most smaller practices and single-handed GPs) and, once set up, there is an expectation that the service will continue even though, over time, the amount of face-to-face contact may have declined 